\title{
Visceral Leishmaniasis in Tunisia: Spatial Distribution and Association with Climatic Factors
}

\author{
Kais Ben-Ahmed, Karim Aoun, Fakhri Jeddi, Jamila Ghrab, Mhamed-Ali El-Aroui, and Aïda Bouratbine* \\ Laboratoire de Recherche 05SP03, Laboratoire de Parasitologie, Institut Pasteur de Tunis, Tunis, Tunisia; Laboratoire de Recherche \\ Opérationnelle de Décision et de Contrôle de Processus, Institut Superieur de Gestion de Tunis, Tunis, Tunisia
}

\begin{abstract}
Visceral leishmaniasis (VL) cases in children less than five years of age were recorded from 1996 through 2006 from Tunisian pediatric departments. Mean incidence rates were calculated for each of the 215 districts in the study area. Averages of annual rainfall and extreme values of low temperatures in winter and high temperatures in summer were used to characterize the climate of each district according to its continentality index and bioclimatic zone. A geographic information system and a local indicator of spatial association were used to summarize the spatial properties of VL distribution. Poisson spatial regression was performed to study the relationship between VL incidence rates and climatic parameters. We identified one hot-spot region of 35 inland districts located mostly in the semi-arid bio-climatic zone and two cold-spots located in coastal regions of the northeastern sub-humid zone and the southeastern arid zone. The incidence rate of VL was positively correlated with mean yearly rainfall and continentality index.
\end{abstract}

\section{INTRODUCTION}

Mediterranean visceral leishmaniasis (MVL) caused by the parasite Leishmania infantum is endemic in almost all countries of the Mediterranean basin. ${ }^{1}$ Dogs are reservoir hosts and the disease is transmitted by the bite of infected female sand flies belonging to the subgenus Laroussius. ${ }^{2}$ In Tunisia, MVL remains primarily a pediatric disease responsible for considerable infantile morbidity and mortality. ${ }^{3}$ Its clinical pattern is typical of the Mediterranean infantile presentation with approximately $90 \%$ of cases among children less than five years of age. ${ }^{4,5}$ The disease is endemic in many foci and is mainly found in the northern and central areas of the country where the climate is favorable to the development of sand flies species of subgenus Laroussius. ${ }^{6}$

Understanding the geographic distribution trends of MVL in Tunisia is essential for identification of the disease risk factors and adjusting control measures to local conditions. Some epidemiologic surveys have previously provided detailed descriptions of the temporal and spatial distribution of the MVL incidence in Tunisia. However, the studied area was limited to central foci. ${ }^{7}$ Unlike this previous work, this ecologic study was based on information from medical records of a large sample of patients in the entire leishmaniasis-endemic area in Tunisia over a period of 11 years. We aimed to estimate MVL incidence rate in Tunisia from 1996 though 2006, to describe the spatial properties of MVL incidence in the country, to identify local clusters with values similar in magnitude, and to analyze climatic and bioclimatic factors that might explain specific patterns.

\section{MATERIALS AND METHODS}

Study area. We studied the 18 governorates of northern and central Tunisia where MVL is known to be endemic. These 18 governorates are divided into 215 districts (Figure 1). The population of the study area is $8,427,762$ persons, of whom $688,618(8.17 \%)$ are children less than five years of age (data available from the Tunisian Institute of Statistics).

*Address correspondence to Aïda Bouratbine, Laboratoire de Parasitologie, Institut Pasteur de Tunis, 13 Place Pasteur, BP 74, 1002 Tunis Belvedère, Tunisia. E-mail: aida.bouratbine@pasteur.rns.tn
MVL data. Data were collected by directly consulting medical records from all pediatric departments and centralizing cases from the 18 governorates. The MVL cases diagnosed from January 1996 through December 2006 (11 years) were thoroughly reviewed. Only reported cases in children less than five years of age were retained for analysis. Patients' addresses were identified at a district level. To ensure confidentiality of the individuals concerned, each MVL patient received a code number so that no one but the responsible physician was able to identify the patients. The number of MVL cases per year was calculated for each district. Annual incidence rate was obtained by taking into account the number of inhabitants less than five years of age (data available from the Tunisian Institute of Statistics). For spatial analysis, the variable retained for each district was the average of annual incidence rates observed during the whole study period (1996-2006).

Climatic data. Climatic data were obtained for 1996-2006 from weather stations measuring precipitation (215 sites) and temperature (26 sites) (data available from Tunisian Institute of Meteorology). Universal kriging (www.gstat.org) was used to interpolate climatic data for districts with missing values. ${ }^{8}$ The interpolated values were estimated at the administrative seats (universal transverse mercator coordinates) of the studied districts. For each district, averages over the period 1996-2006 were calculated for the annual precipitation $(P)$, the minimal temperature of the coldest month $(m)$, and the maximal temperature of the warmest month $(M)$. These data were used to characterize bioclimatic zone and continentality index of each district according to the methods of Daget, ${ }^{9}$ Emberger, ${ }^{10}$ and Debrach. ${ }^{11}$ The pluviometric quotient $\left(\mathrm{Q}_{2}\right)$ of Emberger was computed for each district using the formula $\mathrm{Q}_{2}=1,000 P / 1 / 2(M+m+546.4)(M-m)$ where $P$ is average of annual precipitation in millimeters and $m$ and $M$ are the mean extreme values of low-winter and high-summer temperatures in degree Celsius. Each district was localized according to $\mathrm{Q}_{2}$ and $m$ on the pluviometric climagram of Emberger, which is subdivided into six zones corresponding to as many bioclimatic vegetation stages. These zones are in sequence from the most arid to the most humid, Saharian, arid, semi-arid, sub-humid, and humid stages. Within these bioclimatic zones, sub-types were distinguished according to minimal temperatures of winter (fresh winter $=0-3^{\circ} \mathrm{C}$, temperate winter $3-7^{\circ} \mathrm{C}$, hot winter: $\left.>7^{\circ} \mathrm{C}\right){ }^{10}$ The continentality index was computed in degrees Celsius by the formula $I c=M-m$ and was used to characterize 


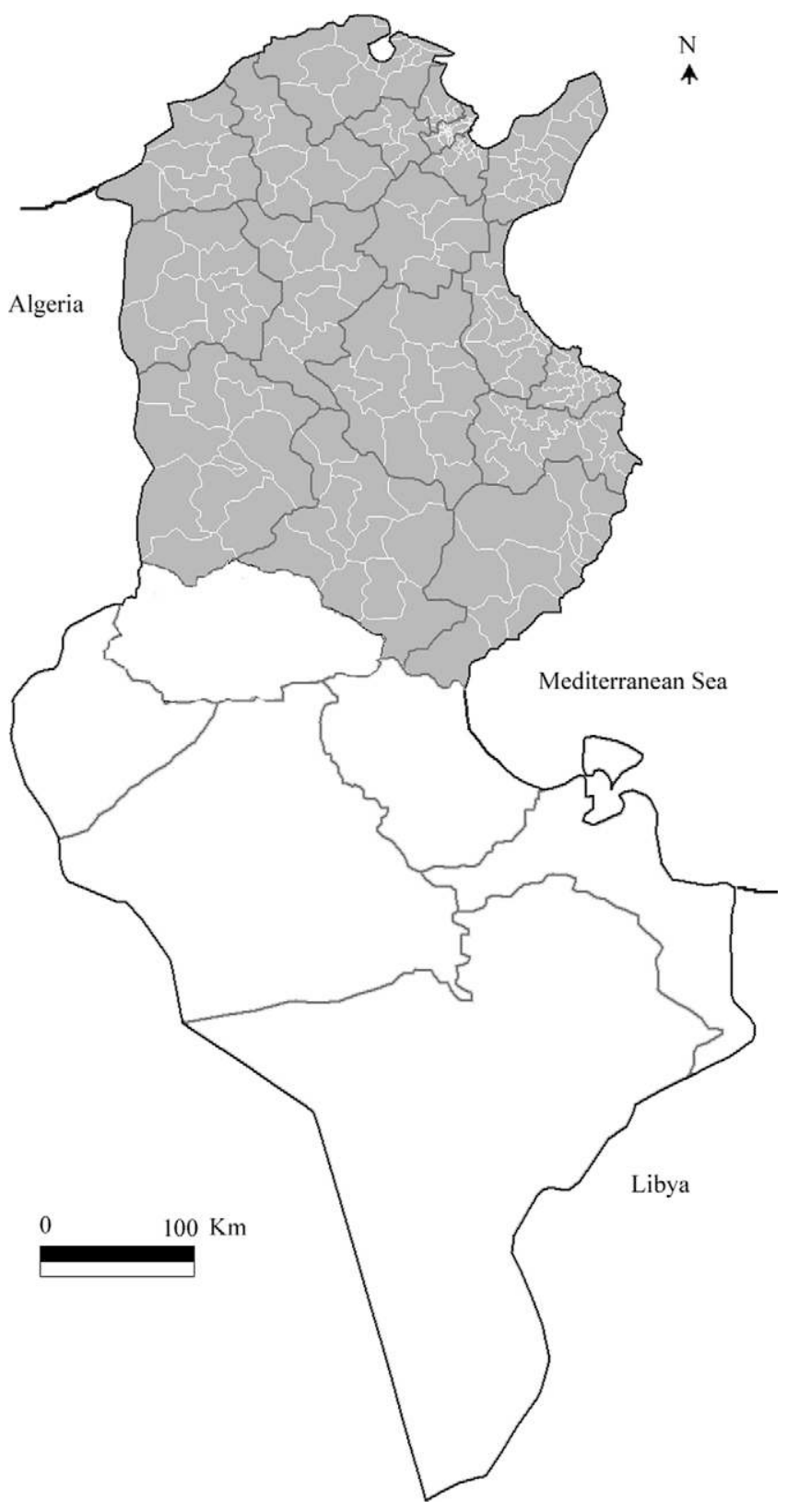

FIgure 1. Study area in Tunisia.

four types of climates: insular $\left(<15^{\circ} \mathrm{C}\right)$, littoral $\left(15-25^{\circ} \mathrm{C}\right)$, semicontinental $\left(25-35^{\circ} \mathrm{C}\right)$, and continental $\left(>35^{\circ} \mathrm{C}\right) .^{11}$

Statistical analysis. On the basis of the digital polygon data for the administrative boundaries of Tunisia, MVL incidence rate was plotted on a map using Arcview GIS (Environmental Systems Research Institute, Redlands, CA). To test whether the map displayed a spatially autocorrelated pattern, the statistic of Moran was used. Spatial autocorrelation was computed globally with the index of Moran and locally with local indicator of spatial association (LISA). ${ }^{12}$ Data handling and statistical analysis were performed with $\mathrm{R}$ statistical packages. Anselin's LISA denoted $I_{\mathrm{i}}$ for region $i$ was computed as $I_{\mathrm{i}}=\left(X_{\mathrm{i}}-\bar{X}\right) * \sum_{\mathrm{j}=1}^{\mathrm{n}} w_{\mathrm{ij}}\left(X_{\mathrm{j}}-\bar{X}\right)$, where $w_{\mathrm{ij}}$ is the $i j$ element of the spatial weight matrix $\left(w_{\mathrm{ij}}\right.$ is inversely related to the distance between districts $i$ and $j$ for $i \neq j$ and $\left.w_{\mathrm{ii}}=0\right), X_{\mathrm{i}}$ and $X_{\mathrm{j}}$ are MVL incidence rates in district $i$ and $j$, respectively, and $\bar{X}$ is the mean incidence rate over all the studied districts. Specific spatial configurations were first identified from a scatter plot showing centered observed values against the weighted mean incidence of their neighbors. Moran's scatter plot makes it possible to identify 1) districts with MVL incidence rates higher than the global average with similar neighbors called high-high and also known as hot-spots, 2) districts with MVL incidence rates lower than average with similar neighbors called low-low and also known as cold-spots, 3) districts with high values of MVL incidence rates with low value neighbors called high-low and also known as potential spatial outliers, and 4) districts with low values of MVL incidence rates with high value neighbors called low-high and also known as potential spatial outliers. Student $t$-test was used to test whether the MVL incidence rate of each district was significantly related to the incidence rates of its neighbors. The LISA values were finally mapped by using Arcview GIS to display geographic distribution of significant hot and coldspots and potential outliers.

A spatial Poisson regression was used to analyze relationships between mean MVL incidence rates and the average climatic parameters. This spatial Poisson regression is based on statistical methods and geoRglm software package (http: //cran.r-project.org) developed by Diggle and others ${ }^{13}$ for the generalized linear spatial models. In this regression, mean MVL incidence rates for the districts was regressed on the mean yearly rainfall and continentality index (the used crosssectional data for the 215 studied districts were the average of annual observations during 1996-2006). A log-link function, a powered-exponential spatial auto-correlation function, and a Bayesian inference framework were used.

\section{RESULTS}

In northern and central Tunisia, 841 MVL patients less than five years of age were recorded from 1996 through 2006. Eight hundred fifteen of them were geographically located at a district level and were retained for statistical analysis. Annual averages of 74 MVL cases and mean incidence rate of 10.75 MVL cases/100,000 children less than five years of age were recorded for the whole study area.

The yearly number of MVL cases from 1996 through 2006 showed an oscillatory pattern with peaks in 1998-2000 and 2005-2006 (Figure 2). A positive correlation was found between the number of MVL cases of the year (y) and the annual rainfall value two years before $(y-2)(r=0.87)$ (Figure 2).

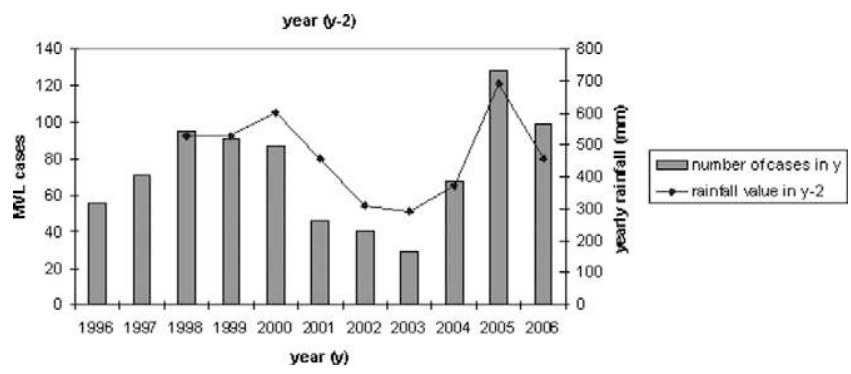

FIGURE 2. Annual number of Mediterranean visceral leishmaniasis cases in 1996-2006 and yearly rainfall in 1996-2004, Tunisia. 
Mean annual incidence rate varied according to the district from 0 to 96.7 MVL cases/100,000 children. Sixty-seven districts located on the eastern coast of the country or in the southern part of the study area had no MLV cases reported during the study period. One hundred forty-eight districts had at least one reported case. These latter districts are largely distributed in the northern and central Tunisia. However, the highest values of incidence rates were shown in the eastern and western parts of northern Tunisia around $39.7^{\circ} \mathrm{N}, 7-8^{\circ} \mathrm{E}$ (Figure 3). The distribution of the disease showed clear spatially auto-correlated patterns (Moran's index $=0.623$ ), which indicated similarity between neighboring districts.

According to Moran's scatter plot results and LISA values, the study area may be divided into three sub-regions. The first region is the high-high region where the disease is homogeneously endemic. This region identified as a hot-spot of 35 inland districts with incidence rates varying from 17.3 to 96.7 cases/100,000 children. The second region is the low-low region where the incidence rate is homogeneously low. Two cold-spots with an incidence rate varying from 0 to 2.2 cases/100,000 children were identified. They were composed of two groups of districts located in coastal regions of northeastern (5 districts) and southeastern (11 districts) Tunisia. The third region is the area where the disease has no homogeneous spatial tendency because the incidence rate of each district is not significantly related to its neighbors (Figure 3 ).

Districts that composed the hot-spot were mostly located in the semi-arid bioclimatic zones with warm winters (32 of 35 ,
A

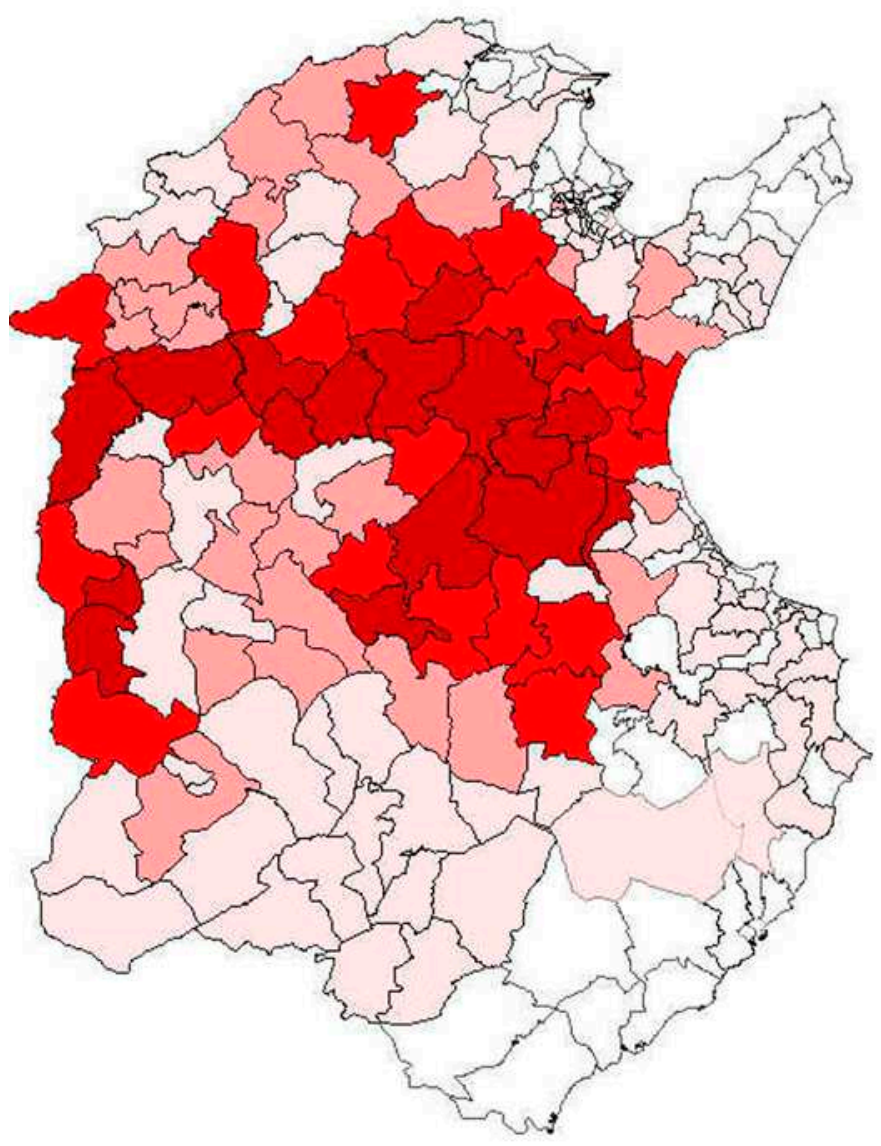

B

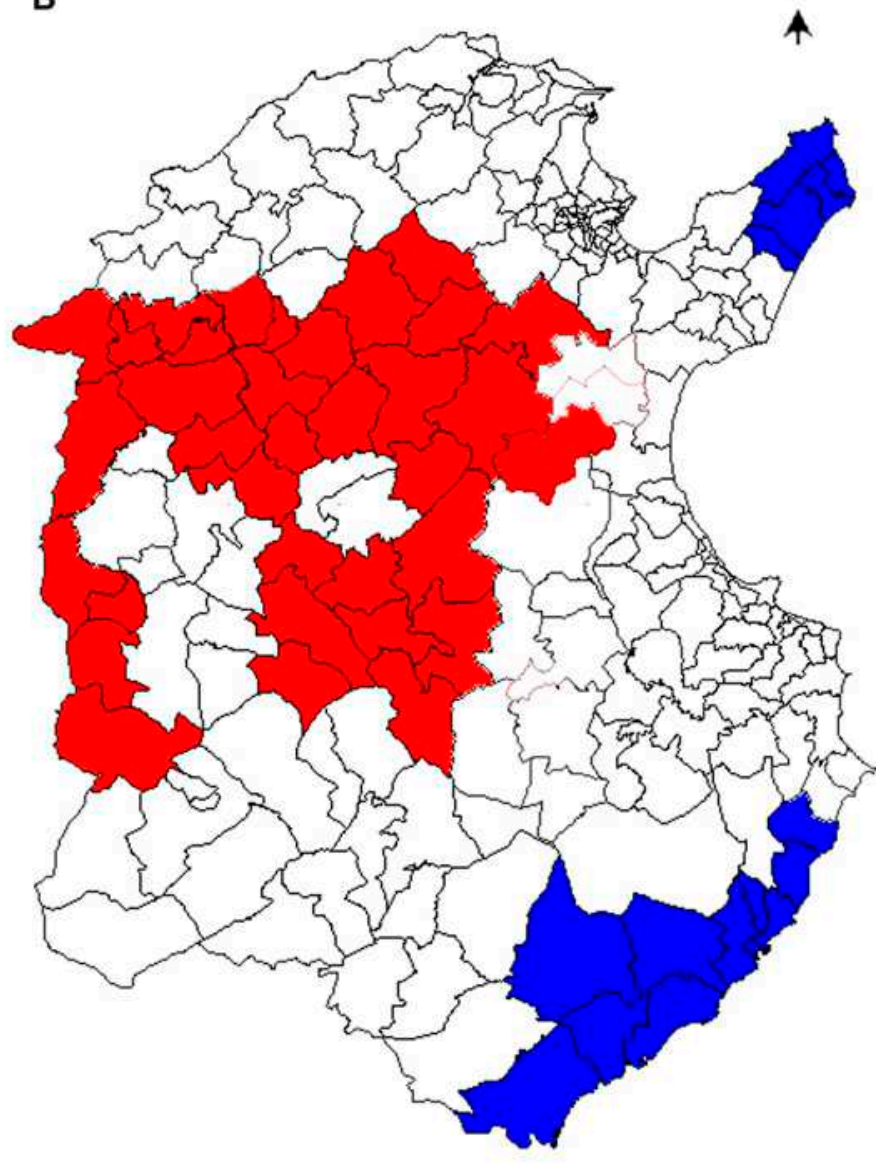

\section{Incidence rate}

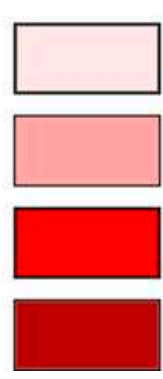

$1.3-12$

$12-24$

$24-48$

$48-96.7$

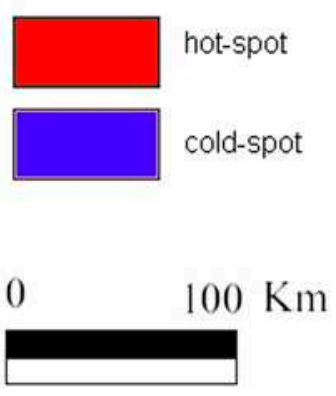

FIgURE 3. Spatial distribution of Mediterranean visceral leishmaniasis (MVL) in northern and central Tunisia. A, Northern and central Tunisia showing mean MVL incidence rate per district. B, Local indicator of spatial association map. This figure appears in color at www.ajtmh.org. 
$91 \%$ ), had mean \pm SD annual rainfall of $495 \pm 77 \mathrm{~mm}$, and had semi-continental climates $\left(I c>30^{\circ} \mathrm{C}\right.$. Districts that composed cold-spots were located in sub-humid zones with hot winters and littoral climates $\left(I c<25^{\circ} \mathrm{C}\right)$ and in arid zones with warm winters and mean annual rainfall $\leq 338 \mathrm{~mm} /$ year (Figure 4). At districts level, the Poisson spatial regression (see Bayesian parameters estimates in Table 1) showed a significant positive relationship between mean MVL incidence rate and mean yearly rainfall and a significant positive relationship between mean MVL incidence rate and the continentality index.

\section{DISCUSSION}

In the past few years, spatial analysis has been increasingly used in the study of leishmaniasis. By using satellite images and field-collected data in Sudan, Thomson and others ${ }^{14}$ and Elnaiem and others ${ }^{15}$ observed that several ecologic factors were crucial for the presence of Phlebotomus orientalis, the vector of VL, in Sudan. Using spatial statistics, MachadoCoelho and others, ${ }^{16}$ Franke and others, ${ }^{17}$ Assunçao and others $^{18}$ and Werneck and others ${ }^{19}$ explored the space-time dynamics of leishmaniasis in Brazil. In Tunisia, Ben Salah and others ${ }^{20}$ carried out a study in the central part of the country. They identified spatio-temporal patterns of zoonotic cutaneous leishmaniasis and correlated them with sociogeographic factors.

This study was designed to contribute to a better understanding of some general trends of MVL in Tunisia by analyzing the temporal and spatial distribution of all diagnosed MVL cases in children less than five years of age during 19962006. First, we attempted to estimate the MVL incidence rate in the whole country from 1996 through 2006. Second, using geographic areas as units of observation, we aggregated MVL incidence rates over the study period, thus neglecting the time dimension. The study of the local level of spatial autocorrelation was then performed to identify areas where values of MVL incidence rate are both extreme and geographically homogenous. Our interest was the identification of these interesting locations, hot-spots and cold-spots with MVL incidence rates similar in magnitude, where common environmental characteristics may have led to a uniform level of transmission risk of the disease. Third, using spatial Poisson models, we modeled rates of disease as a function of aggregate climatic parameters
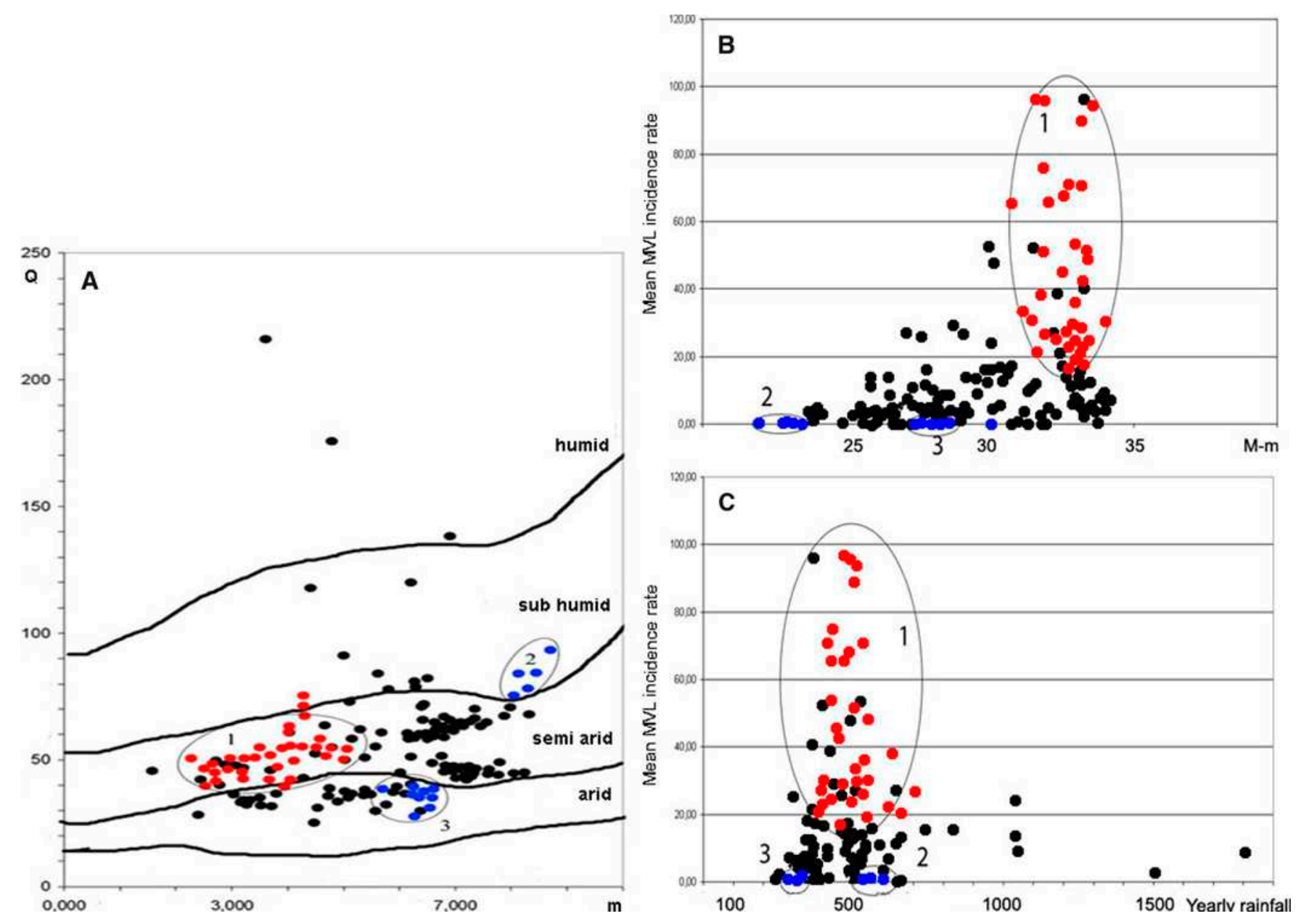

FIGURE 4. Location of a hot-spot and cold-spots according to climatic and bioclimatic parameters in Tunisia. A, Location of districts on Emberger's pluviometric climagram according to their minimal temperature of the coldest month $(m)$ and Emberger's pluviometric quotient $\left(Q_{2}\right)$. B, Location of districts according to continentality index $(M-m)$ and mean incidence rate of Mediterranean visceral leishmaniasis (MVL). C, Location of districts according to yearly rainfall and mean MVL incidence rate. $1=$ hot-spot; 2 and 3 = cold-spots. This figure appears in color at www.ajtmh.org. 
TABLE 1

Poisson spatial regression (Bayesian parameters estimates and 95\% credibility intervals) of leishmaniasis in Tunisia

\begin{tabular}{lcccc}
\hline \multicolumn{1}{c}{ Parameter } & $\begin{array}{c}\text { Posterior } \\
\text { mean }\end{array}$ & $\begin{array}{c}2.5 \% \\
\text { quantile }\end{array}$ & $\begin{array}{c}97.5 \% \\
\text { quantile }\end{array}$ & $\begin{array}{c}\text { Posterior } \\
\text { median }\end{array}$ \\
\hline$\beta_{0}-$ Intercept & -1.701 & -50.015 & 43.034 & -1.87 \\
$\beta_{1}-P$ & $0.00236^{*}$ & 0.00024 & 0.027 & 0.00269 \\
$\beta_{2}-I c$ & $0.089^{*}$ & 0.028 & 0.585 & 0.093 \\
\hline * Indicates parameters that are significant at the 5\% level.
\end{tabular}

over the same time period in the different geographic areas. We attempted this ecologic study of MVL-climate association to examine hypotheses because comparisons were made for groups with presumably different exposures and were not be used to draw causal conclusions.

The MVL data were collected by directly consulting medical records from all pediatric departments in the study area. It is likely that few cases were overlooked because there are no alternative medical centers for treating patients with the disease and anti-leishmanial drugs are restricted for hospital use in Tunisia. Conversely, spatial distribution of MVL cases was analyzed according to patient address. The fact that a child may have traveled to another district where he or she may have been infected was not taken into account. Nevertheless, this hypothesis is difficult to investigate and our data can be useful in giving a rough indication of MVL spatial trend.

The annual number of MVL cases in Tunisia varied over the 11-year period with peaks in 1998-2000 and 2005-2006. Although the time series was not long enough, the temporal trend suggested a recurring 7-8-year cycle. The epidemic wave was followed by a period with relatively lower number of cases. The occurrence of epidemic cycles in VL has been reported in Brazil. ${ }^{17}$ One possible explanation is that during epidemic phases, the pool of susceptible persons in the host population is reduced and the epidemic decreases until the number of susceptible hosts is increased by birth and process repeats itself. ${ }^{17}$ However, this temporal trend also seems to be influenced by climate, and our results suggest that a rainy year is followed two years later by a high number of MVL cases. These results are in concordance with the hypothesis that transmission in humans is probably modulated by the intensity of transmission in the canine reservoir one season before. The increase in L. infantum transmission in the dog population may cause, one year later, a larger pool of infected dogs and thus higher transmission risks to humans. Thus, in the study area, the tendency of rainfall to higher values may have an impact on transmission by influencing abundance of Phlebotomus $(P$.) perfiliewi and/or P. perniciosus, the potential vectors of canine leishmaniasis in these disease-endemic regions. ${ }^{6}$

Mediterranean Visceral leishmaniasis is largely distributed in northern and central Tunisia with a clear spatially autocorrelated pattern. Study of local auto-correlation identified within the disease-endemic area three local clusters, one hotspot and two cold-spots, where common ecologic characteristics may have led to a uniform level of transmission risk. Among the various ecologic factors associated with the distribution of MVL, the abundance of $P$. perniciosus, the main proven vector in most Mediterranean countries, ${ }^{2}$ is a critical factor. A recent entomologic survey in human leishmaniasis sites in Tunisia showed that P. perniciosus is the most abundant Larroussius species in semi-arid bioclimatic zones, whereas in sub-humid and arid areas, this vector species is less abundant. ${ }^{6}$
These results are consistent with those of our study, which showed that the MVL hot-spot is located in semi-arid zone where climatic conditions are favorable for the development of $P$. perniciosus. The presence of cold-spots in sub-humid and arid coastal regions suggests that $P$. perniciosus is rare or absent from these regions.

A significant relationship was found between MVLincidence rate and climatic factors. As mentioned by other authors, ${ }^{21}$ this spatial MVL-climate association suggests that climate change may modify the spatial distribution and incidence of the disease, although the pattern is likely to be specific to the study region. Climate variability may have different effects in transmission that are dependent on particular vectors and various Leishmania species in different regions of the world. ${ }^{21}$

Received November 4, 2008. Accepted for publication March 22, 2009.

Acknowledgments: We thank all collaborators from pediatric departments and from the Regional Public Health Services who enabled and facilitated MVL data collection (Fethi Amri, Hôpital Regional de Kairouan; Sihem Barsaoui, Hôpital d'Enfants, Tunis; Mondher Bjaoui, Direction de Soins de Santé de Base, Tunis; Saïda Ben Bechr, Hôpital d'Enfants, Tunis; Marie-Françoise Ben Dridi, Hôpital la Rabta, Tunis; Asma Bouaziz, Hôpital Regional de Nabeul; Souad Bousnina, Hôpital d'Enfants, Tunis; Moncef Chibani, Hôpital Regional de Zagouan; Essia Dhahbi, Hôpital Regional du Kef; Abdel-Hamid Gnaoui, Hôpital Regional de Jendouba; Monia Hachicha, Hôpital H. Bourguiba, Sfax; Adel Hichri, Hôpital Regional de Béja; Mohamed-Rchid Lakhoua, Hôpital Ch. Nicolle, Tunis; Belgacem Mahmoudi, Hôpital Regional de Kasserine; Ahmed Meherzi, Hôpital Mongi Slim, la Marsa; Ahmed Ourari, Hôpital Regional de Menzel Bourguiba; Azza Sammoud, Hôpital d'Enfants, Tunis).

Financial support: This study was supported by the Ministry of Higher Education, Research and Technology in Tunisia and carried out within the framework of the Research Laboratory Parasitoses Emergentes LR 05 SP03.

Authors' addresses: Kais Ben-Ahmed and Mhamed-Ali El-Aroui, Institut Superieur de Gestion de Tunis, 41 Rue de la Liberté, Bardo 2000, Tunisia. Karim Aoun, Fakhri Jeddi, Jamila Ghrab, and Aïda Bouratbine, LR Parasitoses Emergentes, Laboratoire de Parasitologie, Institut Pasteur de Tunis, 13 Place Pasteur, BP 74,1002 Tunis Belvedère, Tunisia.

Reprint requests: Aïda Bouratbine, Laboratoire de Parasitologie, Institut Pasteur de Tunis, 13 Place Pasteur, BP 74,1002 Tunis Belvedère, Tunisia, E-mail: aida.bouratbine@pasteur.rns.tn.

\section{REFERENCES}

1. Desjeux P, 2004. Leishmaniasis: current situation and new perspectives. Comp Immunol Microbiol Infect Dis 27: 305-318.

2. Killick-Kendrick R, 1990. Phlebotomine vectors of the leishmaniasis: a review. Med Vet Entomol 4: 1-24.

3. Bouratbine A, Aoun K, Chahed MK, Ben Ismaïl R, 1998. Données épidémiologiques sur la leishmaniose viscérale infantile en Tunisie en 1993. Med Mal Infect 28: 446-447.

4. Abdelmoula MS, Mhamdi Z, Amri F, Tebib N, Ben Turkia H, Ben Dridi MF, 2003. La leishmaniose viscérale chez l'enfant. Maghreb Med 23: 40-42.

5. Pousse H, Besbes A, Ben Said M, Ghenimi L, Kharrat H, 1995. Epidemiology of human visceral leishmaniasis in Tunisia. J Trop Pediatr 41: 191-192.

6. Ghrab J, Rhim A, BachHamba D, Chahed MK, Aoun K, Nouira S, Bouratbine A, 2006. Phlebotominae (Diptera: Psychodidae) of human leishmaniosis sites in Tunisia. Parasite 13: 23-33.

7. Ben Salah A, Ben Ismail R, Amri F, Chlif S, Ben Rzig F, Kharrat H, Hadhri H, Hassouna M, Dellagi K, 2000. Investigation of the spread of human visceral leishmaniasis in central Tunisia. Trans $R$ Soc Trop Med Hyg 94: 382-386. 
8. Cressie NA, 1993. Statistics for Spatial Data, Revised Edition. New York: Wiley Interscience, John Wiley and Sons.

9. Daget P, 1977. Le bioclimat Méditerraneen: analyse des formes climatiques par le système d'Emberger. Vegetatio 34: 87-103.

10. Emberger L, 1955. Une classification biogeographique des climats. Rec Trav Lab Bot Geol Zool Fac Sci de Montpellier 7: 3-43.

11. Debrach J, 1953. Notes sur le climat du Maroc occidental. Maroc Méridional 32: 1122-1134.

12. Anselin L, 1995. Local indicators of spatial association-LISA. Geogr Anal 27: 93-115.

13. Diggle PJ, Tawn J, Moyeed R, 1998. Model-based geostatistics. Appl Stat 47: 299-350.

14. Thomson M, Elnaiem DA, Ashford RW, Conner S, 1999. Towards a kala-azar risk map for Sudan: mapping the potential distribution of Phlebotomus orientalis using digital data on environmental variables. Trop Med Int Health 4: 105-113.

15. Elnaiem DE, Schorscher J, Bendall A, Obsomer V, Osman ME, Mekkawi AM, Connor SJ, Ashford RW, Thomson MC, 2003. Risk mapping of visceral leishmaniasis: the role of local variation in rainfall and altitude on the presence and incidence of kala-azar in eastern Sudan. Am J Trop Med Hyg 68: 10-17.
16. Machado-Coelho GL, Assunçao RM, Mayrink W, Caiaffa WT, 1999. American cutaneous leishmaniasis in southeast Brazil: space-time clustering. Int J Epidemiol 28: 982-989.

17. Franke CR, Staubach C, Ziller M, Schluter H, 2002. Trends in the temporal and spatial distribution of visceral and cutaneous leishmaniasis in the state of Bahia, Brazil, from 1985 to 1999. Trans R Soc Trop Med Hyg 96: 236-241.

18. Assunçao RM, Reis IA, Oliveira CL, 2001. Diffusion and prediction of leishmaniasis in a large metropolitan area in Brazil with a Bayesian space-time model. Stat Med 20: 2319-2335.

19. Werneck GL, Costa CH, Walker AM, David JR, Wand M, Maguire JH, 2006. Multilevel modeling of the incidence of visceral leishmaniasis in Teresina, Brazil. Epidemiol Infect 135: 1-7.

20. Ben Salah A, Kamarianakis Y, Chlif S, Ben Alaya N, Prastacos P, 2007. Zoonotic cutaneous leishmaniasis in central Tunisia: spatio-temporal dynamics. Int J Epidemiol 36: 991-1000.

21. Cardenas R, Sandoval CM, Rodriguez-Morales AJ, FrancoParedes C, 2006. Impact of the climate variability in the occurrence of leishmaniasis in northeastern Colombia. Am J Trop Med Hyg 75: 273-277. 